\title{
BMJ Global Health Healthcare-seeking behaviour, barriers and mental health of non-domestic migrant workers in Singapore
}

\author{
Jia Wei Ang, ${ }^{1}$ Colin Chia, ${ }^{2}$ Calvin J Koh, ${ }^{3}$ Brandon W B Chua, ${ }^{4}$ \\ Shyamala Narayanaswamy, ${ }^{5}$ Limin Wijaya, ${ }^{6}$ Lai Gwen Chan, ${ }^{7}$ Wei Leong Goh, ${ }^{2}$ \\ Shawn Vasoo ${ }^{1,8}$
}

To cite: Ang JW, Chia C, Koh CJ, et al. Healthcareseeking behaviour, barriers and mental health of nondomestic migrant workers in Singapore. BMJ Global Health 2017;2:e000213. doi:10.1136/bmjgh-2016000213

- Additional material is available. To view, please visit the journal (http://dx.doi.org/ 10.1136/bmjgh-2016000213).

Received 14 October 2016 Revised 2 February 2017 Accepted 7 February 2017

CrossMark

For numbered affiliations see end of article.

Correspondence to

Dr Shawn Vasoo;

shawn_vasoo@ttsh.com.sg

\section{ABSTRACT}

Background: Low-wage migrant workers are vulnerable to healthcare inequities. We sought to identify potential barriers to healthcare and risk factors for mental health issues in non-domestic migrant workers in Singapore, and identify high-risk subgroups.

Methods: A cross-sectional, interviewer-administered survey of 433 non-domestic migrant workers was conducted at subsidised clinics and a foreign worker dormitory from July to August 2016. Questions assessed healthcare usage patterns, affordability issues, barriers to care and psychological distress using a validated screening scale (Kessler-6).

Findings: Bangladeshi workers surveyed were more likely to be single, have more financial dependents, a lower level of education and salary and pay higher agent fees $(p<0.01) .61 .4 \%$ of workers reported that they had insurance, but had poor understanding of whether it covered inpatient/outpatient expenses. The majority of workers had not, or were not sure if they had, received information about company-bought insurance $(72.4 \%)$. Among those who had, most reported that information was not in their native language (67.7\%). Non-specific psychological distress was found in $21.9 \%$, as estimated by the Kessler-6 scale. Multivariate analysis found that psychological distress was independently associated with Bangladeshi nationals (OR 2.98, $95 \% \mathrm{Cl} 1.58$ to 5.62 ; $\mathrm{p}=0.001$ ) and previous experience of financial barriers to healthcare (OR $3.86,95 \% \mathrm{Cl} 2.25$ to 6.62 ; $p<0.0001)$.

Interpretation: We identified gaps in non-domestic migrant workers' knowledge of healthcare coverage, and substantial financial barriers to healthcare. The Bangladeshi population in our study was at higher risk of such barriers and psychological distress. These represent areas for further research and intervention.

\section{INTRODUCTION}

The United Nations (UN) estimates that international migrants reached 244 million in 2015, with Asia adding 26 million migrants between 2000 and 2015, more than any

\section{Key questions}

What is already known about this topic?

- Migrant workers are at risk of disparities in accessing healthcare, and a lack of access to services may be associated with poorer psychological well-being.

- There are scant data on healthcare-seeking behaviour, associated barriers and the mental health of migrant workers in Southeast Asia, including 'tiger economies' like Singapore, which have large migrant worker populations. It is also unknown if there are subgroups who may be at higher risk of healthcare barriers and poorer psychological health.

What are the new findings?

- Migrant workers working in Singapore, of Bangladeshi origin, compared with those from India or China and other countries, supported more persons in their home country, incurred higher agent fees, had a lower median salary and were more likely to report psychological distress as measured by the Kessler scale.

- Workers who reported financial barriers to accessing healthcare were also more likely to experience psychological distress.

- We found a great degree of indebtedness due to agent fees among migrant workers ( 35\% incurred agent fees of $>S G \$ 5000$ ).

- There was poor knowledge, in general, among migrant workers with regard to eligibility to healthcare coverage and variability in sick leave policy among employers.

other region in the world in the same period. ${ }^{1}$ Half of all international migrants are born in Asia, with India having the biggest diaspora of 16 million persons in 2015. China and Bangladesh had 10 and 7 million persons, respectively. ${ }^{1}$ Most international migrants are of working age, and developing countries were estimated to have received remittances of US $\$ 441$ billion in 2015. ${ }^{2}$ Recognising this trend, and the 


\section{Key questions}

\section{Recommendations for policy}

- More transparent and regulated frameworks in sending and receiving countries may help diminish migrant workers indebtedness.

- Interventions should be directed towards improving the knowledge of migrant workers with regard to their entitled healthcare coverage, and also diminishing financial barriers to accessing care (inpatient and outpatient).

- Subgroups of migrant workers at higher risk of healthcare barriers and psychological distress, such as the Bangladeshi population in our study, should be paid special attention for further research and when formulating health policy and interventions.

important contribution of migrants to home and receiving countries, migration issues, such as achieving universal health coverage and the promotion of a safe and secure working environment for all workers, have been included in the UN 2030 Agenda for Sustainable Development (UN Sustainable Development Goals 3 and 8$).^{3}$

At the crossroads of Asia, Singapore has seen tremendous growth over the past 50 years, with migrant workers essential in fuelling this growth. Many are low or semiskilled workers employed under a short-term contractual basis, performing jobs either in the domestic sector or non-domestic jobs deemed by the local population as 'dirty, dangerous and demanding'- the three Ds. ${ }^{4}$ Most migrant workers in Singapore enter on a 'Work Permit' (for those in the construction, manufacturing, marine, process or services sector) or a 'S Pass' (for midskilled technical staff). In 2015, migrant workers holding Work Permits or S Passes made up 20\% of Singapore's population of 5.54 million people. ${ }^{5}$

Migrant workers health has been a challenging topic deeply intertwined with the history of Singapore, which has seen major regional migratory flows in the past century. ${ }^{6}$ Indeed, most Singaporeans trace their roots to economic migrants who started arriving in the early 1800 s, and migrant workers continue to play an important role in the city-state's economy.

While improvements have been made over recent years with regard to healthcare coverage for migrant workers in Singapore, several gaps still remain. A number of sociocultural and economic factors limit healthcare accessibility and increase vulnerability of low-wage migrant workers in Singapore. They are also subject to increased risk of work-related injury and infectious diseases. ${ }^{7-9}$ Migrant workers do not qualify for medical subsidies and are not covered by the healthcare financing schemes that citizens fall under. ${ }^{10}$ Instead, employers of low and semiskilled workers, holding Work Permits and S Passes, respectively, are legally required to provide inpatient and day surgery medical insurance coverage of $\geq \$ 15000$ a year. $^{11}$ In addition, workers who sustain work injuries or occupational diseases with resulting permanent incapacity or death are liable to compensation under the Work Injury Compensation Act. ${ }^{12}$

The few local studies on migrant workers health have focused on describing commonly faced medical issues such as workplace accidents and infectious diseases. ${ }^{7-9} \mathrm{~A}$ large study on mental health in this vulnerable population in Singapore found an increased rate $(62 \%)$ of psychological distress in migrant workers facing injury claims and salary disputes. ${ }^{13}$ In the larger Asian region, the few studies on the effects of economic migration on mental health have largely focused on the 'left-behind' families of migrant workers. ${ }^{14}{ }^{15}$ One study that did examine the mental health migrants themselves found poorer psychological well-being among Cambodian migrant workers in Thailand who reported poverty, debt and a lack of access to services. ${ }^{16}$ Little has been investigated on perspectives of migrant workers in accessing healthcare. In 2014, Lee et al $l^{17}$ described health-seeking behaviours of male migrant workers found that inadequate finances may impede healthcare-seeking behaviour and also identified low rates of awareness of insurance policies, but did not explore this in depth. In collaboration with a local non-profit organisation, HealthServe, we conducted an observational cross-sectional anonymous survey among low-wage non-domestic migrant workers to better understand the potential barriers they face in accessing healthcare, and their mental health. We also sought to identify subgroups at higher risk of facing healthcare barriers and psychological distress.

\section{METHODS \\ Ethical approval}

This study was approved by the National Healthcare Group's Domain Specific Review Board (DSRB Reference Number: 2016/00499).

\section{Survey design}

Survey questions (see online supplementary appendix A) were designed in consultation with various stakeholders, including doctors, volunteers and HealthServe. Four domains of health-related knowledge, attitude and practices were assessed: current healthcare usage patterns, affordability, other barriers to access and psychological well-being. The Kessler- 6 scale, ${ }^{18}$ a validated screening tool, was used to estimate the prevalence of psychological distress. Demographic information was also included for the assessment of risk factors.

The survey was translated into the native languages of respondents: Bengali, Mandarin and Tamil, and was piloted among migrant workers to ensure feasibility of the questions.

\section{Research site and study population}

Interviewer-administered surveys were administered to workers who visited three HealthServe clinics in Singapore. Migrant workers staying in a dormitory were 
also recruited to ensure broader representation. Singapore Citizens and workers holding Permanent Residency and Employment Passes (skilled professionals with medium to high wages) were excluded. Informed consent was obtained verbally from participants and confidentiality assured as no personal identifiers were collected.

\section{Training of volunteers and data collection}

Volunteer interviewers were recruited to assist in the surveys, and training was conducted to reduce interinterviewer bias. Interviewers were provided with briefing slides of instructions on survey administration. Completed forms were checked after each session to minimise transcribing errors.

\section{Statistical analysis}

We estimated that a sample size of 400 would afford a CI of $\pm 4.9 \%$, at a confidence level of $95 \%$ (http://www.nss. gov.au/nss/home.nsf/). Data analysis was performed using SPSS software (V.24.0). $\chi^{2}$ test, Fishers' exact test and Hodges-Lehmann's median difference test were performed. Backwards-stepwise logistic regression was performed for factors associated (univariate analysis $\mathrm{p}<0.20$ ) with psychological distress as estimated by a Kessler-6 score of $\geq 13$. The Hosmer-Lemeshow test was used to assess goodness-of-fit. A $\mathrm{p}$ value of $<0.05$ indicated statistical significance.

\section{RESULTS}

Over a 5-week period from July to August 2016, 489 low-wage non-domestic migrant workers were invited to participate in the study. Of these, $433(88.5 \%)$ agreed to participate. Three hundred and twenty-nine (76.0\%) were clinic visitors and $104(24.0 \%)$ were non-clinic visitors from a dormitory.

\section{Sociodemographic characteristics}

The median age of workers surveyed was 31 (IQR, 27-38) (table 1$)$. The majority were men $(99.1 \%)$, Bangladeshi $(67.7 \%)$ and employed in the construction industry (71.7\%). Two per cent were unemployed $(n=11)$.

Comparing the Bangladeshi and non-Bangladeshi workers, the proportions of Bangladeshis who were single (OR 1.9, 95\% CI 1.2 to 2.9 ) and supported $\geq 7$ people (OR 6.96, 95\% CI 3.12 to 15.5 ) were significantly higher. They were also more likely to work in the shipyard/marine industry (OR 2.80, 95\% CI 1.45 to 5.38), were less likely to have received a postsecondary education (OR 0.46, 95\% CI 0.30 to 0.71), had a lower median salary of SG\$700 (IQR, 571-900; $<<0.0001$ ) and paid higher amounts of agent fees.

\section{Healthcare usage patterns and self-reported insurance coverage}

Most workers had seen a doctor in Singapore before (83.8\%), with Bangladeshi workers more likely to have performed so (OR 2.35, 95\% CI 1.39 to 3.96), and to have visited four or more healthcare facilities in the past year (OR 2.14, 95\% CI 1.38 to 3.31) (table 2). Only $61.4 \%$ of workers were certain they had medical insurance coverage, while $20.9 \%$ were unsure. Sixty-three per cent were unsure if their insurance covered outpatient expenses; $10 \%$ reported that their coverage excluded outpatient costs.

\section{Barriers to healthcare and perception of healthcare financing}

Twenty-two per cent of workers surveyed reported having ever experiencing financial barriers in accessing healthcare in Singapore (respondents answering in the affirmative to survey questions C1a, C1b or C1c, see online supplementary appendix A; indicated in table 3 as those who cited cost as a reason for ever (1) not seeking medical care, (2) avoiding referrals to a specialist/tertiary medical centre or (3) not filling a prescription). This was associated with having paid agent fees of $>$ SG $\$ 10000(p=0.01)$. When asked whether any information was provided regarding their company-bought insurance policies, only $15.2 \%$ responded 'Yes'. Among these, $32.3 \%$ received it in their native languages. Bangladeshi workers were significantly less likely to receive this information (OR $0.49,95 \%$ CI 0.29 to 0.84 ) and have it in their native language (OR $0.32,95 \%$ CI 0.11 to 0.94$)$.

More workers perceived that in the event of a hospitalisation, they would have to self-pay if it was not work injury-related $(32 \%)$, than if the expenses were incurred from a work injury $(6.8 \%)$. Fewer respondents (19.9\%) reported insurance playing a role in the payment of non-work injury-related, compared with work injury-related (40.3\%), expenses. Most workers (63\%) were also unsure if their medical insurance covered outpatient costs.

A majority reported that their employers recognised sick leave in the form of medical certificates (MCs). However, $12.5 \%$ said that only MCs from their company doctors were accepted. In addition, $26.5 \%$ and $7.5 \%$ of workers reported that withholding and deduction, respectively, of daily wages (even with a valid sick/outpatient MC) was practiced in their company. The reported wage withholding and deduction rates for respondees with hospitalisation leave were $24.9 \%$, and $4.5 \%$, respectively.

\section{Psychological distress}

Twenty-two per cent of workers surveyed were at higher risk of psychological distress as indicated by a Kessler- 6 (K6) score of $\geq 13$. This was associated with age, nationality, employment status, basic monthly salary, amount of agent fees, type of entry visa and experience with financial barriers to healthcare (table 4). However, it was not associated with gender, number of people supported, marital status, highest education completed, working hours, number of rest days, duration in Singapore, 


\begin{tabular}{|c|c|c|c|c|c|c|}
\hline \multirow[b]{2}{*}{ Characteristic (number of respondents, $n$ ) } & \multirow[b]{2}{*}{ Bangladeshi† $(\mathrm{N}=293)$} & \multirow[b]{2}{*}{ Indian $(\mathrm{N}=85)$} & \multirow[b]{2}{*}{ Chinese $(\mathrm{N}=52)$} & \multirow[b]{2}{*}{ All $(\mathrm{N}=433)$} & \multicolumn{2}{|c|}{$\begin{array}{l}\text { Bangladeshi vs } \\
\text { non-Bangladeshi (reference } \\
\text { category)† }\end{array}$} \\
\hline & & & & & p Value & OR $(95 \% \mathrm{Cl})$ \\
\hline \multicolumn{7}{|l|}{ Age } \\
\hline Median (IQR) & $30(26-35)$ & $30(26-36)$ & $45(41-49)$ & $31(27-38)$ & $<0.0001 \ddagger$ & - \\
\hline \multicolumn{7}{|l|}{ Gender } \\
\hline Male, no. (\%) & $293(100)$ & $84(99)$ & $50(96)$ & $429(99)$ & $0.011 \S$ & - \\
\hline \multicolumn{7}{|l|}{ Marital status $(n=432)$} \\
\hline Married, no. (\%) & $170(58)$ & $48(57)$ & $50(96)$ & $269(62)$ & 0.008 & 0.56 (0.36 to 0.86$)$ \\
\hline Single, no. (\%) & $123(42)$ & $36(43)$ & $1(2)$ & $162(38)$ & 0.005 & $1.9(1.2$ to 2.9$)$ \\
\hline Separated, no. (\%) & $0(0)$ & $0(0)$ & $1(2)$ & $1(0.2)$ & $0.32 \S$ & - \\
\hline Number of people supported, median (IQR) $(n=431)$ & $5(4-7)$ & $5(3.5-5)$ & $4(2-4.8)$ & $5(4-6)$ & $<0.0001 \ddagger$ & - \\
\hline \multicolumn{7}{|l|}{ Number of people supported $(n=431)$} \\
\hline 3 or less, no. (\%) & $54(19)$ & $21(25)$ & $24(46)$ & $100(23)$ & 0.001 & $0.47(0.29$ to 0.74$)$ \\
\hline 4 to 6 , no. $(\%)$ & $159(55)$ & $61(71)$ & $24(46)$ & $246(57)$ & 0.11 & $0.73(0.49$ to 1.1$)$ \\
\hline 7 or more, no. (\%) & $78(27)$ & $3(4)$ & $4(8)$ & $85(20)$ & $<0.0001$ & $7.0(3.1$ to 16$)$ \\
\hline \multicolumn{7}{|l|}{ Work industry $(n=431)$} \\
\hline Construction, no. (\%) & $208(71)$ & $61(72)$ & $40(78)$ & $309(72)$ & 0.76 & $0.93(0.59$ to 1.5$)$ \\
\hline Shipyard/marine, no. (\%) & $61(21)$ & $11(13)$ & $1(2)$ & $73(17)$ & 0.002 & $2.8(1.5$ to 5.4$)$ \\
\hline Maintenance, no. (\%) & $14(5)$ & $11(13)$ & $2(4)$ & $28(7)$ & 0.038 & 0.45 (0.21 to 0.97$)$ \\
\hline Othersףl, no. (\%) & $9(3)$ & $2(2)$ & $8(16)$ & $21(5)$ & 0.012 & $0.34(0.14$ to 0.82$)$ \\
\hline Currently unemployed, no. (\%) $(n=433)$ & $7(2)$ & $0(0)$ & $4(8)$ & $11(3)$ & $0.75 \S$ & 0.83 (0.24 to 2.9$)$ \\
\hline \multicolumn{7}{|l|}{ Highest education completed $(n=433)$} \\
\hline Primary or less, no. (\%) & $31(11)$ & $9(11)$ & $9(17)$ & $49(11)$ & 0.48 & $0.80(0.43$ to 1.5$)$ \\
\hline Secondary, no. (\%) & $195(67)$ & $33(39)$ & $33(64)$ & $262(61)$ & $<0.0001$ & $2.2(1.4$ to 3.3$)$ \\
\hline Postsecondary, no. (\%) & $67(23)$ & $43(51)$ & $10(19)$ & $122(28)$ & $<0.0001$ & $0.46(0.30$ to 0.71$)$ \\
\hline Basic monthly salary (SG\$), median (IQR) $(n=420)$ & $700(570.5-900)$ & $800(600-1000)$ & $1950(1600-2000)$ & $800(600-1000)$ & $<0.0001 \ddagger$ & - \\
\hline Average working hours/week, median (IQR) $(n=417)$ & $60(54-70)$ & $60(48-66)$ & $64(60-70)$ & $60(54-70)$ & $0.34 \ddagger$ & - \\
\hline Number of rest days/month, median (IQR) $(n=417)$ & $4(2-4)$ & $4(2-4)$ & $4(2-4)$ & $4(2-4)$ & $0.11 \neq$ & - \\
\hline Duration in Singapore (years), median (IQR) $(n=429)$ & $6(4-9)$ & $6(3-9)$ & $5(3.3-9)$ & $6(4-9)$ & $0.21 \neq$ & - \\
\hline \multicolumn{7}{|l|}{ Type of entry visa $(n=429)$} \\
\hline Work permit & $279(96)$ & $80(94)$ & $42(86)$ & $403(94)$ & 0.041 & $2.3(1.0$ to 5.0$)$ \\
\hline S Pass & $5(2)$ & $5(6)$ & $5(10)$ & $16(4)$ & 0.001 & 0.20 (0.07 to 0.59$)$ \\
\hline
\end{tabular}




\begin{tabular}{|c|c|c|c|c|c|c|}
\hline \multirow[b]{2}{*}{ Characteristic (number of respondents, $n$ ) } & \multirow[b]{2}{*}{ Bangladeshi† ( $\mathrm{N}=293)$} & \multirow[b]{2}{*}{ Indian $(\mathrm{N}=85)$} & \multirow[b]{2}{*}{ Chinese $(\mathrm{N}=52)$} & \multirow[b]{2}{*}{ All $(\mathrm{N}=433)$} & \multicolumn{2}{|c|}{$\begin{array}{l}\text { Bangladeshi vs } \\
\text { non-Bangladeshi (reference } \\
\text { category)† }\end{array}$} \\
\hline & & & & & p Value & OR (95\% Cl) \\
\hline Special pass & $6(2)$ & $0(0)$ & $2(4)$ & $8(2)$ & $1.00 \S$ & $1.4(0.28$ to 7.1$)$ \\
\hline Multiple journey visa & $2(0.7)$ & $0(0)$ & $0(0)$ & $2(0.5)$ & $1.00 \S$ & - \\
\hline \multicolumn{7}{|c|}{ Amount of agent fees paid to come to Singapore, no. $(\%)(n=421)$} \\
\hline None & $29(10)$ & $8(10)$ & $7(14)$ & $45(11)$ & 0.68 & $0.87(0.46$ to 1.7$)$ \\
\hline SG $\$ 1000$ and less & $6(2)$ & $4(5)$ & $0(0)$ & $10(2)$ & $0.74 \S$ & $0.73(0.20$ to 2.6$)$ \\
\hline SG\$1001-SG $\$ 5000$ & $123(44)$ & $61(73)$ & $26(51)$ & $211(50)$ & $<0.001$ & $0.44(0.29$ to 0.66$)$ \\
\hline SG\$5001-SG\$10 000 & $98(35)$ & $10(12)$ & $13(26)$ & $122(29)$ & $<0.001$ & 2.5 (1.5 to 4.2$)$ \\
\hline SG\$10 001 and above & $13(5)$ & $1(1)$ & $5(10)$ & $19(5)$ & 0.91 & $1.1(0.39$ to 2.9$)$ \\
\hline Unsure & $14(5)$ & $0(0)$ & $0(0)$ & $14(3)$ & $0.006 \S$ & - \\
\hline \multicolumn{7}{|c|}{ Current amount of agent fee owed, no. (\%) $(n=421)$} \\
\hline None & $232(82)$ & $61(73)$ & $48(94)$ & $344(82)$ & 0.84 & $1.1(0.63$ to 1.78$)$ \\
\hline SG $\$ 1000$ and less & $7(2.5)$ & $3(4)$ & $1(2)$ & $11(3)$ & $0.76 \S$ & 0.85 (0.24 to 3.0$)$ \\
\hline SG\$1001-SG\$5000 & $27(10)$ & $10(12)$ & $1(2)$ & $38(9)$ & 0.60 & $1.2(0.59$ to 2.5$)$ \\
\hline SG\$5001-SG\$10 000 & $9(3)$ & $9(11)$ & $1(2)$ & $19(5)$ & 0.059 & $0.42(0.17$ to 1.1$)$ \\
\hline SG\$10 001 and above & $1(0.4)$ & $1(1)$ & $0(0)$ & $2(0.5)$ & $0.55 \S$ & $0.49(0.03$ to 7.8$)$ \\
\hline Unsure & $7(2)$ & $0(0)$ & $0(0)$ & $7(2)$ & $0.10 \S$ & - \\
\hline
\end{tabular}

${ }^{*} \mathrm{p}$ Values by Pearson $\chi^{2}$ test except otherwise indicated. Reference population used for $\mathrm{p}$ values and OR are non-Bangladeshis.

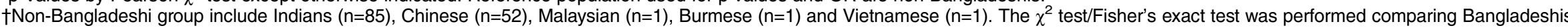
versus non-Bangladeshis (the latter being the reference category).

$\neq p$ Values by independent-samples Hodges-Lehmann's median difference.

$\S p$ Values by Fisher's exact test.

१Others include: gardening $(n=4)$, manufacturing $(n=3)$, food and beverages $(n=3)$, ad hoc workers $(n=2)$, other miscellaneous jobs $(n=9)$.

SG\$, Singapore dollars. 
Table 2 Healthcare usage and self-reported insurance coverage of non-domestic migrant workers, HealthServe clinics and foreign worker dormitory, 23 July-28 August 2016*

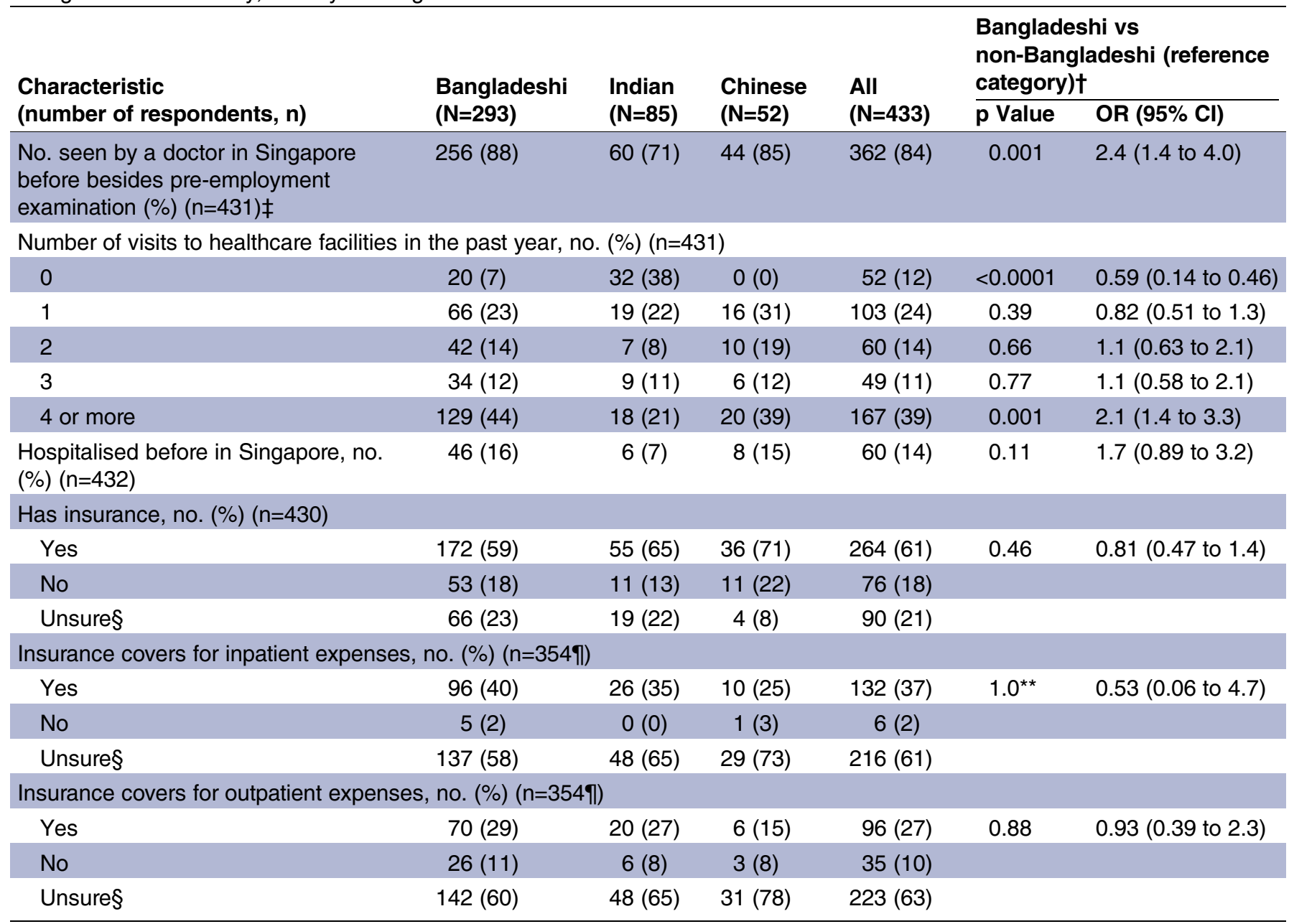

${ }^{*} p$ Values by Pearson $\chi^{2}$ test except otherwise indicated. Reference population used for $p$ values and OR are non-Bangladeshis. †Non-Bangladeshi group include Indians $(n=85)$, Chinese $(n=52)$, Malaysian $(n=1)$, Burmese $(n=1)$ and Vietnamese $(n=1)$. The $\chi^{2}$ test was performed comparing Bangladeshis versus non-Bangladeshis (the latter being the reference category). This section consists of questions to which answers were 'Yes', 'No' and 'Unsure' except when stated otherwise. 'Unsure' responses were not included in the statistical analysis. $\ddagger$ These include healthcare visits to public and private hospitals/clinics, specialist centres like the National Skin Centre and other non-profit clinics.

TExcluded those who answered that they have no insurance $(n=76)$.

$\S$ 'Unsure' responses were not included in the $\chi^{2}$ test.

${ }^{* \star} p$ Values by Fisher's exact test.

current agent fees owed or presence of chronic medical problems.

Multiple logistic regression analysis showed that factors independently increasing the risk of psychological distress were Bangladeshi nationality (OR 2.98, 95\% CI 1.58 to 5.62) and previous experience of financial barriers to healthcare (OR $3.86,95 \%$ CI 2.25 to 6.62 ) (table 5). Online supplementary appendix B details the breakdown of K6 scores.

\section{DISCUSSION}

A substantial number of workers appeared to have poor understanding of healthcare expenses financing. Despite policies protecting migrant workers financially in the event of hospitalisation, ${ }^{11}$ many workers still thought that they had no insurance, or were expected to pay the bills completely. Many had misconceptions that insurance cannot cover non-work-related hospitalisations. Furthermore, it appears that a majority of the workers surveyed were unclear about the payment of outpatient medical bills, in particular whether this was covered by their insurance policies. Current medical insurance guidelines for employers of migrant workers in Singapore stipulate a coverage of SG $\$ 15000 /$ year to cover inpatient care and day surgery, including hospital bills for conditions that may not be work-related, ${ }^{19}$ but are silent on outpatient coverage.

A possible cause for the deficiencies in knowledge is the widespread practice by employers of not providing information on insurance policies. Even when provided, this was rarely in their native language. Bangladeshis were most commonly affected by this in our study. This is not surprising as the native languages of the two other 
Table 3 Barriers to healthcare and self-reported perception of payment of inpatient expenses among non-domestic migrant workers, HealthServe clinics and foreign worker dormitory, 23 July-28 August 2016*

\section{Characteristic \\ (number of} respondents, $\mathbf{n}$ )

$\begin{array}{lll}\begin{array}{l}\text { Bangladeshi } \\ (\mathrm{N}=281)\end{array} & \begin{array}{l}\text { Indian } \\ (\mathrm{N}=84)\end{array} & \begin{array}{l}\text { Chinese } \\ (\mathrm{N}=51)\end{array}\end{array}$

Bangladeshi vs non-Bangladeshi (reference category)†

Did not seek medical care because of cost $(n=432)$

\begin{tabular}{|c|c|c|c|c|c|c|}
\hline Yes & $57(20)$ & $9(11)$ & $14(27)$ & $81(19)$ & 0.58 & 1.2 (0.69 to 2.0 \\
\hline No & $235(81)$ & 75 (88) & $38(73)$ & $350(81)$ & & \\
\hline Unsureł & $0(0)$ & $1(1)$ & $0(0)$ & $1(0.2)$ & & \\
\hline
\end{tabular}

Did not get prescription medications because of cost $(n=432)$

\begin{tabular}{|c|c|c|c|c|c|c|}
\hline Yes & $34(12)$ & $3(4)$ & $10(19)$ & $47(11)$ & 0.47 & $1.3(0.65$ to 2.5$)$ \\
\hline No & 257 (88) & $82(97)$ & $41(79)$ & $383(89)$ & & \\
\hline Unsure‡ & $1(0.3)$ & $0(0)$ & $1(2)$ & $2(0.5)$ & & \\
\hline
\end{tabular}

Did not get specialist care or referral to tertiary hospital because of cost $(n=432)$

\begin{tabular}{|c|c|c|c|c|c|c|}
\hline Yes & $40(14)$ & $5(6)$ & $10(19)$ & $56(13)$ & 0.50 & $1.2(0.67$ to 2.3$)$ \\
\hline No & $249(85)$ & $80(94)$ & $41(79)$ & $372(86)$ & & \\
\hline Unsureł & $3(1)$ & $0(0)$ & $1(2)$ & $4(0.9)$ & & \\
\hline \multicolumn{7}{|c|}{ Insurance policy/information provided $(n=429)$} \\
\hline Yes & $34(12)$ & $23(27)$ & $8(16)$ & $65(15)$ & 0.009 & 0.49 (0.29 to 0.84$)$ \\
\hline No & $215(74)$ & $55(65)$ & $38(79)$ & $311(73)$ & & \\
\hline Unsure & $41(14)$ & $7(8)$ & $5(10)$ & $53(12)$ & & \\
\hline \multicolumn{7}{|c|}{ Insurance information in native language $\S(n=65)$} \\
\hline Yes & $7(20)$ & $12(52)$ & $2(25)$ & $21(32)$ & 0.034 & $0.32(0.11$ to 0.94$)$ \\
\hline No & 27 (79) & $11(48)$ & $6(75)$ & $44(68)$ & & \\
\hline
\end{tabular}

Who pays for work-related injury hospitalisations $\uparrow(n=429)$

\begin{tabular}{lcccccc} 
Self only & $16(6)$ & $2(2)$ & $10(20)$ & $29(7)$ & 0.16 & $0.58(0.27$ to 1.2$)$ \\
\hline Insurance has role & $125(43)$ & $29(34)$ & $18(35)$ & $173(40)$ & 0.10 & $1.4(0.93$ to 2.2) \\
Unsure & $15(5)$ & $2(2)$ & $2(4)$ & $19(4)$ & - & - \\
Who pays for non-work injury-related hospitalisations $(\mathrm{n}=428)$ & & & \\
Self only & $82(28)$ & $19(22)$ & $35(69)$ & $137(32)$ & 0.018 & $0.59(0.38$ to 0.92$)$ \\
Insurance has role & $64(22)$ & $16(19)$ & $4(8)$ & $85(20)$ & 0.08 & $1.6(0.94$ to 2.8) \\
Unsure & $30(10)$ & $6(7)$ & $8(16)$ & $44(10)$ & - & -
\end{tabular}

Employer recognises MC from company doctor $(n=256)^{\star *}$

\begin{tabular}{|c|c|c|c|c|c|c|}
\hline Yes & $163(90)$ & $53(96)$ & $12(63)$ & $229(90)$ & $1.0+t$ & 0.71 (0.14 to 3.5$)$ \\
\hline No & $7(4)$ & $1(2)$ & 1 (5) & $9(4)$ & & \\
\hline Unsure‡ & $11(6)$ & $1(2)$ & $6(32)$ & $18(7)$ & & \\
\hline
\end{tabular}

Employer recognises MC from private general practitioner $(n=427)$

$\begin{array}{lcccccc}\text { Yes } & 209(73) & 67(79) & 29(57) & 307(72) & 0.73 & 0.91(0.53 \text { to } 1.6) \\ \text { No } & 54(19) & 12(14) & 11(22) & 77(18) & & \\ \text { Unsureł } & 25(9) & 6(7) & 11(22) & 43(10) & \end{array}$

Employer recognises MC from HealthServe clinic $(n=427)$

$\begin{array}{lrrrrrr}\text { Yes } & 194(67) & 59(69) & 27(53) & 282(66) & 0.49 & 0.82(0.46 \text { to } 1.5) \\ \text { No } & 54(19) & 9(11) & 11(22) & 74(17) & & \\ \text { Unsureł } & 40(14) & 17(20) & 13(26) & 71(17) & \end{array}$

Employer recognises MC from government polyclinic/hospital $(n=427)$

\begin{tabular}{lccrrrr} 
Yes & $236(82)$ & $71(84)$ & $31(61)$ & $340(80)$ & 0.57 & $1.2(0.62$ to 2.4$)$ \\
No & $28(10)$ & $8(9)$ & $7(14)$ & $43(10)$ & & \\
Unsure & $24(8)$ & $6(7)$ & $13(26)$ & $44(10)$ & \\
\hline
\end{tabular}


Table 3 Continued

\begin{tabular}{|c|c|c|c|c|c|c|}
\hline \multirow{2}{*}{$\begin{array}{l}\text { Characteristic } \\
\text { (number of } \\
\text { respondents, } n \text { ) }\end{array}$} & \multirow{2}{*}{$\begin{array}{l}\text { Bangladeshi } \\
(\mathrm{N}=\mathbf{2 8 1})\end{array}$} & \multirow{2}{*}{$\begin{array}{l}\text { Indian } \\
(\mathrm{N}=84)\end{array}$} & \multirow{2}{*}{$\begin{array}{l}\text { Chinese } \\
(\mathrm{N}=51)\end{array}$} & \multirow[b]{2}{*}{ All $(\mathrm{N}=419)$} & \multicolumn{2}{|c|}{$\begin{array}{l}\text { non-Bangladeshi (reference } \\
\text { category)t }\end{array}$} \\
\hline & & & & & p Value & OR (95\% Cl) \\
\hline \multicolumn{7}{|c|}{ Only MCs from company doctors are accepted $(n=255)^{\star *}$} \\
\hline Yes & $24(13)$ & $7(13)$ & $1(5)$ & $32(13)$ & 0.67 & $1.2(0.51$ to 2.8$)$ \\
\hline No & $137(76)$ & $45(82)$ & $10(53)$ & $192(75)$ & & \\
\hline Unsure & $19(11)$ & $3(6)$ & $8(42)$ & $31(12)$ & & \\
\hline \multicolumn{7}{|c|}{ Daily wages held if on sick/outpatient MC $(n=426)$} \\
\hline Yes & $68(24)$ & $17(20)$ & $28(55)$ & $113(27)$ & 0.025 & $0.60(0.38$ to 0.94$)$ \\
\hline No & $208(73)$ & $62(73)$ & $18(35)$ & $290(68)$ & & \\
\hline Unsureł & $11(4)$ & $6(7)$ & $5(10)$ & $23(5)$ & & \\
\hline \multicolumn{7}{|c|}{ Daily wages held if on hospitalisation MC $(n=426)$} \\
\hline Yes & $69(24)$ & $11(13)$ & $26(51)$ & $106(25)$ & 0.37 & $0.81(0.50$ to 1.3$)$ \\
\hline No & $192(67)$ & $64(75)$ & $18(35)$ & $275(65)$ & & \\
\hline Unsure & $26(9)$ & $10(12)$ & $7(14)$ & $45(11)$ & & \\
\hline \multicolumn{7}{|c|}{ Had pay deducted even with sick/outpatient MC $(n=426)$} \\
\hline Yes & $22(8)$ & $4(5)$ & $6(12)$ & $32(8)$ & 0.92 & $1.0(0.48$ to 2.3$)$ \\
\hline No & $258(90)$ & 78 (92) & $42(82)$ & $380(89)$ & & \\
\hline Unsure & $7(2)$ & $3(4)$ & $3(6)$ & $14(3)$ & & \\
\hline \multicolumn{7}{|c|}{ Had pay deducted even with hospitalisation MC $(n=425)$} \\
\hline Yes & $12(4)$ & $1(1)$ & $6(12)$ & $19(5)$ & 0.67 & $0.81(0.31$ to 2.1$)$ \\
\hline No & $259(91)$ & $81(95)$ & $40(78)$ & $382(90)$ & & \\
\hline Unsure & $15(5)$ & $3(4)$ & $5(10)$ & $24(6)$ & & \\
\hline \multicolumn{7}{|c|}{ Knows someone with pay deducted even with sick/outpatient MC $(n=424)$} \\
\hline Yes & $55(19)$ & $6(7)$ & $10(20)$ & $71(17)$ & 0.043 & $1.9(1.0$ to 3.4$)$ \\
\hline No & $208(73)$ & $75(88)$ & $35(69)$ & $320(76)$ & & \\
\hline Unsureł & $22(8)$ & $4(5)$ & $6(12)$ & $33(8)$ & & \\
\hline \multicolumn{7}{|c|}{ Knows someone with pay deducted even with hospitalisation MC $(n=423)$} \\
\hline Yes & $38(13)$ & $4(5)$ & $8(16)$ & $50(12)$ & 0.14 & $1.7(0.84$ to 3.3$)$ \\
\hline No & $218(77)$ & $77(91)$ & $36(71)$ & $333(79)$ & & \\
\hline Unsure & $28(10)$ & $4(5)$ & $7(14)$ & $40(10)$ & & \\
\hline \multicolumn{7}{|c|}{ Afraid of losing job or being sent home if fall sick $(n=422)$} \\
\hline Yes & $76(27)$ & $9(11)$ & $12(24)$ & $97(23)$ & 0.010 & $2.0(1.8$ to 3.4$)$ \\
\hline No & $202(71)$ & $72(86)$ & $38(75)$ & $315(74)$ & & \\
\hline Unsure & $6(2)$ & $3(4)$ & $1(2)$ & $10(2)$ & & \\
\hline
\end{tabular}

${ }^{*} p$ Values by Pearson $\chi^{2}$ test except otherwise indicated. Reference population used for $p$ values and OR are non-Bangladeshis. This section consists of questions to which answers were 'Yes', 'No' and 'Unsure' except when stated otherwise. 'Unsure' responses were not included in the statistical analysis. MC, medical certificate.

†Non-Bangladeshi group include Indians $(n=85)$, Chinese $(n=52)$, Malaysian $(n=1)$, Burmese $(n=1)$ and Vietnamese $(n=1)$.

$\neq$ 'Unsure' responses were not included in the $\chi^{2}$ test.

$\S$ Three hundred and sixty-five who answered 'No' and 'Unsure' to having been provided a copy of their health insurance policy were excluded. ๆRespondents were given scenarios and asked for who (among company, insurance and self) they thought was responsible for payment of medical bills, multiple selections were allowed.

${ }^{* *}$ One hundred and seventy-one respondents who have no company doctor were excluded.

t†p Values by Fisher's exact test.

large ethnic groups of non-Bangladeshi migrant workers, Tamil (for most Indian migrant workers) and Mandarin (for Chinese migrant workers), are official languages in Singapore.

Overall rates of psychological distress $(21.9 \%)$ were slightly higher than what was previously found among non-injury or salary claim workers $(13 \%) .{ }^{13}$ Only $3 \%$ of our survey population were unemployed (eg, due to an injury-claim). In addition, we identified Bangladeshi nationality and previous financial barriers to healthcare to be independent significant risk factors. Though payment of a high agent fee was a variable identified in 
Table 4 Characteristics of non-domestic migrant workers with psychological distress assessed by Kessler- 6 score of 13 or higher, HealthServe clinics and foreign worker dormitory, 23 July-28 August $2016^{*}$

\begin{tabular}{|c|c|c|c|c|}
\hline $\begin{array}{l}\text { Characteristic (number of } \\
\text { respondents, } n \text { ) }\end{array}$ & $\begin{array}{l}\text { Kessler- } 6 \text { score of } \\
13 \text { or higher }(\mathrm{N}=92 \text {, } \\
21.9 \%)\end{array}$ & $\begin{array}{l}\text { Kessler-6 score of } 12 \\
\text { or lower (reference } \\
\text { group) }(\mathrm{N}=328,78.1 \%)\end{array}$ & p Value & OR $(95 \% \mathrm{Cl})$ \\
\hline Age, median (IQR) $(n=420)$ & $29.5(26.0,34 \square .5)$ & $32.0(27.0,38.5)$ & $0.047 \dagger$ & - \\
\hline \multicolumn{5}{|l|}{ Gender, no. (\%) (n=420) } \\
\hline Male & 91 (99) & 325 (99) & $1.0 \ddagger$ & $0.84(0.09$ to 8.2$)$ \\
\hline \multicolumn{5}{|l|}{ Nationality, no. (\%) (n=420) } \\
\hline Indian & $8(9)$ & $75(23)$ & 0.003 & $0.32(0.15$ to 0.70$)$ \\
\hline Chinese & $9(10)$ & $42(13)$ & 0.43 & $0.74(0.35$ to 1.6$)$ \\
\hline Others & $0(0)$ & $3(0.9)$ & $1.00 \ddagger$ & - \\
\hline \multicolumn{5}{|l|}{ Marital status, no. $(\%)(n=419)$} \\
\hline $\begin{array}{l}\text { Number supported, median (IQR) } \\
(n=418)\end{array}$ & $5(4,6)$ & $5(4,6)$ & 0.91 & - \\
\hline \multicolumn{5}{|l|}{ Work industry, no. (\%) (n=418) } \\
\hline Construction & $66(73)$ & $234(71)$ & 0.71 & $1.1(0.65$ to 1.9$)$ \\
\hline Shipyard & $18(20)$ & $52(16)$ & 0.35 & $1.3(0.73$ to 2.4$)$ \\
\hline Maintenance & $4(4)$ & $24(7)$ & 0.33 & $0.59(0.20$ to 1.7$)$ \\
\hline Others & $2(2)$ & $18(6)$ & $0.27 \ddagger$ & $0.39(0.09$ to 1.7$)$ \\
\hline Unemployed $(n=420)$ & $8(9)$ & $1(0.3)$ & $<0.0001 \ddagger$ & 31 (3.84 to 253 ) \\
\hline \multicolumn{5}{|c|}{ Highest education completed, no. (\%) $(n=420)$} \\
\hline $\begin{array}{l}\text { Number of rest days/month, } \\
\text { median (IQR) }(n=407)\end{array}$ & $4(2,4)$ & $4(2,4)$ & $0.26 \dagger$ & - \\
\hline $\begin{array}{l}\text { Duration in Singapore, years, } \\
\text { median (IQR) }(n=417)\end{array}$ & $6(4,9)$ & $6(3,9)$ & $0.85 \dagger$ & - \\
\hline \multicolumn{5}{|l|}{ Agent fees (SG\$), no. (\%) $(n=420)$} \\
\hline None & $8(9)$ & $37(11)$ & 0.48 & $0.75(0.34$ to 1.7$)$ \\
\hline 1000 and less & $2(2)$ & $8(2)$ & 0.88 & $0.89(0.19$ to 4.3$)$ \\
\hline $1001-5000$ & $40(44)$ & $170(53)$ & 0.16 & $0.72(0.46$ to 1.1$)$ \\
\hline $5001-10000$ & $29(32)$ & $93(28)$ & 0.55 & $1.2(0.71$ to 1.9$)$ \\
\hline 10001 and above & $9(10)$ & $10(3)$ & $0.011 \ddagger$ & 3.5 (1.4 to 9.8$)$ \\
\hline \multicolumn{5}{|c|}{ Current amount owed (SG\$), no. (\%) $(n=420)$} \\
\hline None & $71(77)$ & $272(83)$ & 0.21 & $0.70(0.40$ to 1.2$)$ \\
\hline 1000 and less & $2(2)$ & $9(3)$ & $1.00 \ddagger$ & $0.79(0.17$ to 3.7$)$ \\
\hline $1001-5000$ & $11(12)$ & 27 (8) & 0.27 & 1.5 (0.72 to 3.2$)$ \\
\hline $5001-10000$ & $5(5)$ & $14(4)$ & $0.58 \ddagger$ & $1.3(0.45$ to 3.7$)$ \\
\hline 10001 and above & $1(1)$ & $1(0.3)$ & $0.39 \ddagger$ & $3.6(0.22$ to 58$)$ \\
\hline
\end{tabular}


Table 4 Continued

\begin{tabular}{|c|c|c|c|c|}
\hline $\begin{array}{l}\text { Characteristic (number of } \\
\text { respondents, } n \text { ) }\end{array}$ & $\begin{array}{l}\text { Kessler- } 6 \text { score of } \\
13 \text { or higher }(\mathrm{N}=92 \text {, } \\
21.9 \%)\end{array}$ & $\begin{array}{l}\text { Kessler-6 score of } 12 \\
\text { or lower (reference } \\
\text { group) }(\mathrm{N}=328,78.1 \%)\end{array}$ & p Value & OR $(95 \% \mathrm{Cl})$ \\
\hline \multicolumn{5}{|c|}{ Type of entry visa, no. (\%) $(n=417)$} \\
\hline Work permit & $82(89)$ & $311(96)$ & 0.017 & $0.37(0.16$ to 0.86$)$ \\
\hline S Pass & $4(4)$ & $12(4)$ & $0.76 \ddagger$ & $1.2(0.37$ to 3.8$)$ \\
\hline Special pass & $6(7)$ & $0(0)$ & $<0.0001 \ddagger$ & - \\
\hline Multiple journey visa & $0(0)$ & $2(0.6)$ & $1.00 \ddagger$ & - \\
\hline \multicolumn{5}{|c|}{ Chronic medical problems, no. (\%) $(n=419)$} \\
\hline Yes & $10(11)$ & $24(7)$ & 0.26 & $1.6(0.72$ to 3.4$)$ \\
\hline \multicolumn{5}{|c|}{ Financial barriers reported§, no. $(\%)(n=420)$} \\
\hline Yes & $39(42)$ & $54(17)$ & $<0.001$ & 3.7 (2.3 to 6.2$)$ \\
\hline \multicolumn{5}{|c|}{$\begin{array}{l}\text { * } p \text { Values by Pearson } \chi^{2} \text { test. Reference population used for } p \text { values and OR are those with Kessler- } 6 \text { score } 12 \text { or less. } \\
t p \text { Values by independent-samples Hodges-Lehmann's median difference test. } \\
\neq p \text { Values by Fisher's exact test. } \\
\text { §Respondents who answered 'Yes' to the following questions: during your time in Singapore, was there any time when, because of cost (a) you } \\
\text { did not seek medical care; (b) needed prescription medications but did not get them or (c) needed specialist care but did not do so? } \\
\text { SG\$, Singapore dollars }\end{array}$} \\
\hline
\end{tabular}

our univariate analysis and Harrigan et $a l,{ }^{13}$ it was not statistically significant in our multivariate model.

The Bangladeshi workers surveyed, who were three times as likely to have a Kessler score $\geq 13$, had other significant differences from workers of other nationalities, including lower salary and educational levels, more financial dependents and higher agent fees. Lower salaries and having to financially support more people were previously identified by Lee et $a l^{17}$ as risk factors for not seeking care within 3 days of illness, though nationality was not an independent risk factor. In our study, although Bangladeshi workers appear to have risk factors for not seeking care, they were a group which sought healthcare more frequently. This could be due to their cultural influences on illness beliefs, or a greater level of anxiety over health problems, as a manifestation of the greater psychological distress faced by this group.

Another factor relating to psychological distress (Kessler Score $\geq 13$ ) was the presence of financial barriers to healthcare (OR, 3.8). Almost a fifth of respondents reported having ever not sought care because of cost. In 2008, the Ministry of Manpower, Singapore, introduced compulsory medical insurance for migrant workers. In 2010, the minimum coverage for medical insurance (inpatient and day surgery) was raised from
SG\$5000 to SG\$15 000/year. While these represent positive improvements in healthcare coverage for migrant workers, our findings suggest that significant gaps may remain. While not directly addressed by our study, feedback from various stakeholders (migrants, nongovernmental organisations and healthcare providers) indicates that a significant proportion of migrants (especially those with chronic illnesses) do not have outpatient insurance coverage, and may not be able to afford outpatient medical fees. In addition, the ceiling of SG $\$ 15000$ for inpatient/day-surgery fees may be easily breached in the event of catastrophic illness/ injury. These factors, along with concern over losing their job/repatriation in the event of illness, ${ }^{17}$ may contribute to reluctance to seek medical care. Future studies should explore in greater depth the healthcare economics among low-wage migrant workers in Singapore.

Lee et $a l^{17}$ found that a perception of inadequate finances hindered healthcare access (specifically, selfreported health-seeking behaviour) among male migrant workers. We found a significant degree of initial and current indebtedness incurred due to agent fees among migrant workers in our study. Indebtedness (specifically, agent fees $>$ SG\$10 000) was associated with self-

Table 5 Multiple logistic regression model for risk factors associated with psychological distress as measured by Kessler-6 score 13 or more among non-domestic migrant workers*

\begin{tabular}{lllll}
\hline Variable & Coefficient $(\boldsymbol{\beta})$ & SE & p Value & OR (95\% CI) \\
\hline Nationality (Bangladeshi†) & 1.09 & 0.32 & 0.001 & $3.0(1.6$ to 5.6$)$ \\
Financial barriers reported $\neq$ & 1.35 & 0.28 & $<0.0001$ & $3.9(2.3$ to 6.6$)$
\end{tabular}

\footnotetext{
*Variables included in backward stepwise logistic regression analysis: age, nationality, unemployed status, basic monthly salary, amount of agent fees paid, type of entry visa, financial barriers. This model was well fitted with a Hosmer-Lemeshow statistic of 0.97 .

†Bangladeshi versus non-Bangladeshi (reference group).

†Respondents who answered 'yes' to the following questions: During your time in Singapore, was there any time when, because of cost (a) you did not seek medical care; (b) needed prescription medications but did not get them or (c) needed specialist care but did not do so?
} 
reported financial barriers to seeking healthcare and poorer mental health (as indicated by a Kessler-6 score of >13) on univariate analysis. Our findings that selfreported financial barriers had a significant effect on mental health (multivariate analysis, $\mathrm{p}<0.0001$ ) corroborate those from recent survey by H.O.M.E, a Singaporebased non-governmental organisation for migrant workers, which found that debt significantly affected the mental health of Filipino migrant domestic workers. ${ }^{20}$ Debt-financed migration adds to the inherent precarity associated with migrant labour, ${ }^{21}$ impedes health-seeking behaviour and adds to mental stress faced by migrant workers.

Regarding sick leave policies, $12.5 \%$ of workers with company doctors said that their employer only recognised medical leave from their company doctors. According to employment regulations for work permit holders in Singapore, all sick leave must be endorsed by a company or a government (public institution) doctor. Salary deductions are permissible for unauthorised absence from work or if sick leave is not authorised and the employer suffers loss as a result (eg, from having to employ a replacement). This sometimes leads to a conflict in the doctor-patient relationship (eg, authorising an inadequate duration of sick leave) when there is a contractual relationship (formal or otherwise) between healthcare providers and the employer. ${ }^{22}$ In our study, $26.5 \%$ and $24.9 \%$ of migrant workers reported that their daily wages were not paid, for outpatient and hospitalisation sick leave, respectively, even if they had documentation from a doctor (whether company, government or others). A further $7.6 \%$ (with outpatient sick leave) and $4.5 \%$ (with hospitalisation leave) reported having salary deductions (on top of wages being withheld for day(s) of absence).

\section{Limitations}

First, as we surveyed mostly healthy workers who never faced catastrophic illnesses, our study may not represent the full spectrum of healthcare experiences and beliefs of migrant workers. In addition, most of those surveyed had access to low-cost outpatient care at HealthServe clinics; potentially biasing (underestimating) responses about care limitations and healthcare usage patterns. However, interviewing workers in this setting, without the presence of employers, provided a more private setting for respondents to be open in sharing their experiences.

In addition, there could be some degree of interinterviewer bias, and misinterpretation due to language barriers. These were minimised by having translated surveys, and interpreters were available during the conduct of the survey. Training and supervision for interviewers were also provided.

There were no validated Tamil and Bengali translations of the Kessler-6 scale available which may affect the assessment of psychological distress. We sought to overcome this limitation by having our translated versions independently verified by native-speakers.

Finally, this study was conducted in Singapore, which is a high-income, non-OECD country. Facets of the migrant healthcare experience described in this study might be specific to Singapore; however, we believe that

Table 6 Suggested priority areas for study and interventions to improve migrant health and deliver

\begin{tabular}{|c|c|}
\hline Area & Notes \\
\hline $\begin{array}{l}\text { 1. Migrant worker indebtedness } \\
\text { and job security }\end{array}$ & $\begin{array}{l}\text { Improving regulatory framework and transparency in the sending countries vis-à-vis } \\
\text { the application process and related fees for prospective migrant workers seeking jobs } \\
\text { Receiving countries, in collaboration with sending countries, may consider } \\
\text { direct-hiring, or hiring via more regulated process(es) } \\
\text { Improve protective framework for the job security of migrant workers, including } \\
\text { protection from arbitrary repatriation/dismissal, lack of income while awaiting case } \\
\text { settlement/after loss of work permit and improved avenues for redress }\end{array}$ \\
\hline 3. Migrant worker mental health & $\begin{array}{l}\text { Specific subgroups of migrant workers may be at risk of mental health issues and } \\
\text { other healthcare barriers, and should be the focus of further research and } \\
\text { interventions }\end{array}$ \\
\hline
\end{tabular}


the Singapore experience might mirror other midincome to high-income receiving countries.

\section{Implications}

Our results reflect a degree of information asymmetry which can result in workers avoiding seeking care, or preferring to be repatriated for fear of unaffordable healthcare. This is a possible area where intervention to increase policy awareness could be carried out. In addition, we identified subgroups of migrant workers at higher risk of poor mental health, for which further research is needed to determine root causes and effects. Self-reported rates of errant practices (eg, salary withholding or deductions despite outpatient or hospitalisation leave) potentially highlight an area where tighter enforcement is necessary. Based on findings from our study, we propose several key areas policymakers in sending and receiving countries, healthcare providers and other non-governmental organisations should focus on to improve migrant health (table 6).

Although the focus of this study was on healthcare accessibility and mental health, we recognise that there are other factors, such as beliefs, lifestyle and preventive measures, which influence population health. Further work should be performed on these other health determinants in migrant workers.

\section{CONCLUSIONS}

We identified potential barriers to healthcare among low-wage non-domestic migrant workers in Singapore. These include knowledge gaps and financial barriers. The reasons for these are probably multifaceted and merit further study. The Bangladeshi workers in our study are possibly at higher risk of psychological distress and poor knowledge, and might represent a more vulnerable subgroup for intervention.

\author{
Author affiliations \\ ${ }^{1}$ Lee Kong Chian School of Medicine, Nanyang Technological University, \\ Singapore \\ ${ }^{2}$ HealthServe Community Clinic, Singapore \\ ${ }^{3}$ Division of Gastroenterology and Hepatology, National University Hospital, \\ National University Health System, Singapore \\ ${ }^{4}$ Department of Pharmacy, KK Women's and Children's Hospital, Singapore \\ ${ }^{5}$ Department of Pharmacy, Singapore General Hospital, Singapore \\ ${ }^{6}$ Department of Infectious Diseases, Singapore General Hospital, Singapore \\ ${ }^{7}$ Department of Psychiatry, Tan Tock Seng Hospital, Singapore \\ ${ }^{8}$ Department of Infectious Diseases, Institute of Infectious Diseases and \\ Epidemiology, Tan Tock Seng Hospital, Singapore
}

\section{Handling editor Seye Abimbola.}

Acknowledgements The authors would like to thank the volunteers who helped to administer this survey: From the Class of 2018-2021, the Lee Kong Chian School of Medicine, Aishwarya Narayanan, Ang Wee Kiat, Chew Yi Rong, Claudia Tong Ren Hwee, Joel Wong, Joshua Tan, Kiang Wen Wei, Justin Liu Shuang, Melissa Chia, Moses Ko, Poon Yee Jun, Toh Wen Shien, Wong Chun Jie and Yap Hong Wan; Volunteers from HealthServe: Carissa Lim, Christine Toh, Colin Seow, Lim Kang Le, Lim Ying Fu, Ruthra, Seow Han Cong, Shane Wu, Sherilyn Chew, Sumitha Grace Pandjaraja, Utthra, Wong Kit Yarn and Yi Xin. The authors also record their thanks to Musfiqul Islam, Dong Muyun and Manavala Reuben for translating the survey into Bengali,
Mandarin and Tamil, respectively, and also the staff and volunteers of HealthServe for their support for this study. Above all, the authors acknowledge and thank the migrant workers who participated in this survey, without whom this study would not have been possible.

Contributors JWA and SV designed the study and survey questions, managed the data set, performed the statistical analysis and wrote the first and subsequent drafts of the report. CC, BWBC, SN, LGC WLG, CJK and LW contributed to the study and survey design, reviewed and commented on the drafts of the report. CC and WLG facilitated the conduct of the survey at the HealthServe clinic and its outreach programme. All authors approved the final submitted version of the manuscript. SV had full access to all the data in the study and assumes final responsibility for the decision to submit for publication.

\section{Competing interests None declared}

Ethics approval National Healthcare Group Domain Specific Review Board F.

Provenance and peer review Not commissioned; externally peer reviewed.

Data sharing statement The data collected from the surveys described in this manuscript can be shared by the authors on request.

Open Access This is an Open Access article distributed in accordance with the Creative Commons Attribution Non Commercial (CC BY-NC 4.0) license, which permits others to distribute, remix, adapt, build upon this work noncommercially, and license their derivative works on different terms, provided the original work is properly cited and the use is non-commercial. See: http:// creativecommons.org/licenses/by-nc/4.0/

\section{REFERENCES}

1. United Nations, Department of Economic and Social Affairs, Population Division. Population Facts. Trends in international migration, 2015. Dec 2015; No. 2015/4. http://www.un.org/en/ development/desa/population/migration/publications/populationfacts/ docs/MigrationPopFacts20154.pdf (accessed 1 Mar 2017).

2. World Bank Group, Global Knowledge Partnership on Migration and Development. Migration and remittances fact book: 2016. 3rd edn. http://siteresources.worldbank.org/INTPROSPECTS/Resources/ 334934-1199807908806/4549025-1450455807487/Factbookpart1. pdf (accessed 1 Mar 2017).

3. United Nations, Transforming our world: the 2030 Agenda for Sustainable Development. https://sustainabledevelopment.un.org/ post2015/transformingourworld (accessed 30 Sep 2016).

4. Yap MT, Koh G, Soon D, et al. Migration and integration in Singapore: policies and practice. Chapter 1, Immigration and intergration in Singapore, Page 27. London, New York: Routledge, 2015.

5. Ministry of Manpower, Singapore. Foreign Workforce Numbers. 2016. http://www.mom.gov.sg/documents-and-publications/ foreign-workforce-numbers (accessed 10 Sep 2016).

6. Amrith SS. Migration and health in Southeast Asian history. Lancet 2014;384:1569-70.

7. Ngo CS, Leo SW. Industrial accident-related ocular emergencies in a tertiary hospital in Singapore. Singapore Med J 2008;49:280-5.

8. Ong VYK, Habibah AK, Lee FCY. Safety among foreign workers and impact on emergency medicine services in Singapore. Singapore Med J 2006;47:121-8.

9. Lee GK, Tan KW, Goh KT, et al. Trends in importation of communicable diseases into Singapore. Ann Acad Med Singapore 2010;39:764-70.

10. Guinto RLLR, Curran UZ, Suphanchaimat R, et al. Universal health coverage in 'One ASEAN': are migrants included? Glob Health Action 2015;8:25749.

11. Ministry of Manpower, Singapore. Employment of Foreign Manpower (Work Passes) Regulations. 2015. http://www.mom.gov.sg/ legislation/employment-of-foreign-manpower-act (accessed $10 \mathrm{Sep}$ 2016).

12. Ministry of Manpower, Singapore. Work Injury Compensation Act Singapore. 2009. http://www.mom.gov.sg/ workplace-safety-and-health/work-injury-compensation (accessed 10 Sep 2016).

13. Harrigan N, Koh CY. Vital Yet Vulnerable: Mental and Emotional Health of South Asian Migrant Workers in Singapore. Research Collection School of Social Sciences. Paper 1764. 2015. https:// 
centres.smu.edu.sg/lien/files/2012/03/Vital-Yet-Vulnerable.pdf (accessed 30 Sep 2016).

14. Graham E, Jordan LP. Migrant parents and the psychological well-being of left-behind children in Southeast Asia. J Marriage Fam 2011;73:763-87.

15. Wickramage K, Siriwardhana C, Vidanapathirana $\mathrm{P}$, et al. Risk of mental health and nutritional problems for left-behind children of international labor migrants. BMC Psychiatry 2015;15:39.

16. Meyer SR, Robinson WC, Chhim S, et al. Labor migration and mental health in Cambodia: a qualitative study. J Nerv Ment Dis 2014;202:200-8.

17. Lee W, Neo A, Tan S, et al. Health-seeking behaviour of male foreign migrant workers living in a dormitory in Singapore. BMC Health Serv Res 2014;14:300.

18. Kessler RC, Barker PR, Colpe LJ, et al. Screening for serious mental illness in the general population. Arch Gen Psychiatry 2003;60:184-9.
19. Ministry of Manpower, Singapore. Medical insurance requirements for foreign worker. http://www.mom.gov.sg/passes-and-permits/ work-permit-for-foreign-worker/sector-specific-rules/ medical-insurance (accessed 10 Sep 2016)

20. Humanitarian Organisation for Migration Economics (H.O.M.E.) 'Home sweet home? Work, life and well-being of foreign domestic workers in Singapore'. Research Report. 2015. http://www.home.org.sg/wp-content/uploads/2015/07/HOME_ 2015_Home-sweet-home_short.pdf (accessed 20 Dec 2016).

21. Platt M, Baey G, Yeoh BSA, et al. Debt, precarity and gender: male and female temporary labour migrants in Singapore. J Ethn Migr Stud 2016:43:119-36.

22. TODAY. Doc suspended over inadequate MCs for foreign worker. 12 May 2016. http://www.todayonline.com/singapore/ landmark-ruling-against-doctor-ngos-say-inadequate-mcsmigrant-workers-still-problem (accessed 1 Oct 2016) 